\title{
Early High Frequency Oscillatory Ventilation in Pediatric Acute Respiratory Failure
}

\author{
AHMED M. ABD-ELGAWAD, M.Sc.; KHALED T. ABU-EALA, M.D.; SAHAR A. ABD-ELAZIZ, M.D. and \\ AHMED I. HARKAN, M.D.
}

The Department of Pediatrics, Faculty of Medicine, Tanta University

\begin{abstract}
Background: High frequency oscillatory ventilation (HFOV) has been a staple in the management of children with acute respiratory failure (ARF). HFOV is a mode of mechanical ventilation that recruits diseased lung and improves oxygenation through the use of high mean airway pressures with tidal volumes less than anatomic dead space. Although HFOV is commonly used in children, efficacy data are limited and predate the era of low tidal volume $\left(\mathrm{V}_{\mathrm{t}}\right)$ conventional mechanical ventilation (CMV).
\end{abstract}

Aim of the Study: It was to compare the impact of early high frequency oscillatory ventilation (within 24-48 hours of endotracheal intubation) to conventional mechanical ventilation and/or late high frequency oscillatory ventilation in children with acute respiratory failure.

Patients and Methods: The study was carried out on thirty patients with acute respiratory failure (ARF) who attended to the pediatric intensive care unit, Pediatric Department, Tanta University Hospital. All studied children were subjected to detailed history taking, complete physical examination, monitoring of SV, SVI, CO, CI, SVR, SVRI through transesophageal doppler monitoring and oxygenation index.

Results: There was significant decrease of O2Sat of Early HFOV group compared with P-CMV and Late HFOV. there was significant increase of $\mathrm{O}_{2}$ Sat in Early HFOV in 2 nd and $3^{\text {rd }}$ days compared with 1 st day There was significant decrease of oxygenation index in late HFOV and P-CMV groups compared with Early HFOV group. It is one of most important prognostic factors for detection timing of HFOV according to ROC curve.

Conclusion: As hypoxia worsened, patient percentage with Early HFOV increased Oxygenation index was significant as a predictor and prognostic factor for early HFOV success.

Key Words: HFOV - Trans-esophageal doppler monitoring of $C O$.

Correspondence to: Dr. Ahmed M. Abd-Elgawad, The Department of Pediatric, Faculty of Medicine, Tanta University

\section{Introduction}

HIGH frequency oscillatory ventilation (HFOV) has been a staple in the management of children with acute respiratory failure (ARF). HFOV is a mode of mechanical ventilation that recruits diseased lung and improves oxygenation through the use of high mean airway pressures with tidal volumes less than anatomic dead space. Although HFOV is commonly used in children, efficacy data are limited and predate the era of low tidal volume $(\mathrm{Vt})$ conventional mechanical ventilation (CMV) [1] . Cardiac output (CO) is the volume of blood that is pumped by the heart around the systemic circulation in one minute [2]. The interplay of preload, contractility, heart rate and afterload results in $\mathrm{CO}$ control [3]

Continuous mandatory ventilation (CMV) may be insufficient to maintain adequate gas exchange in seriously ill patients and may also cause or aggravate lung injury. HFOV has been used to improve gas exchange in patients who cannot be adequately ventilated by conventional means, while limiting lung injury [4]

Theoretically, HFOV achieves the goals of protective ventilation by optimizing alveolar recruitment through sustained high mean airway pressures, while avoiding lung trauma associated with the swings in pressure associated with conventional methods [5]

Although HFOV is used frequently in ICUs, there are few systematic studies of its hemodynamic (HD) effects 14 years ago. The results of studies using different experimental models have not been consistent. So, it remains unclear as to what, if any, HD consequences should be anticipated when switching from CMV to HFOV [6]. It is known from numerous animal and human studies that 
increasing mean airway pressure during CMV adversely affects $\mathrm{CO}$. This reduction in CO could adversely affect oxygen delivery and potentially be harmful. Studies on the effect of HFOV on CO have produced conflicting results. HFOV has been reported not to alter left ventricular output (LVO) in experimental studies and in children [7]. The timing of introduction of HFOV and the claims of its better physiological effects raise the questions on its other effects on HD comparing it to CMV.

\section{Aim of the work:}

It was to compare the impact of early high frequency oscillatory ventilation (within 24-48 hours of endotracheal intubation) to conventional mechanical ventilation and/or late high frequency oscillatory ventilation in children with acute respiratory failure.

\section{Patients and Methods}

This prospective study was carried out upon 30 pediatric patients with ARF (aged from 2-108 months) admitted in PICU, Tanta University Hospital. The duration of research was from December 2016 to December 2017

Patients were divided into 3 groups: Group I (Early HFOV): Fifteen patients were monitored on HFOV.Group II (Late HFOV): Five patients were monitored on HFOV (24hr post-intubation). Group III (P-CMV): Ten patients were monitored on P-CMV. Exclusion criteria: Patient to be extubated within 24 hours. Patients suffering from cardiac arrhythmias. Severe valvular regurgitation (severe aortic and mitral regurgitation) and Complex congenital heart disease.

All the studied patients were subjected to the following: Full history taking, clinical examination, routine investigations (complete blood count, creactive protein), scoring systems for patients (PRISM III and SOFA), monitoring of SV, SVI, CO, CI, SVR, SVRI through trans-esophageal doppler monitoring and oxygenation index.

Statistical presentation and analysis of the present study was conducted using the mean, standard deviation, student $t$-test, Chi-square test with $p<0.05$ means significance, Regression analysis and ROC curve

\section{Results}

This prospective study was carried out upon 30 pediatric patients with ARF admitted in PICU, Tanta University Hospital, all patients were cross matched for age and sex.
Table (1) show that regarding demographic and anthropometric data of the Studied Patients. There was no statistically significant difference throughout the study between the studied groups as regard age, sex, height and weight.

Table (1): Demographic and laboratory data of the studied groups.

Table (2): Comparison of Oxygen Saturation (\%) between the Studied Groups.

There was statistically significant decrease of $\mathrm{O}_{2}$ Sat of Early HFOV compared with P-CMV and Late HFOV in 1 st 2 nd and 3 rd days.

Comparison inside each group:

- There was statistically significant increase in Early HFOV in 2 nd and 3 rd days compared with 1 st day.

- There was statistically significant increase in Late HFOV in 2 nd and 3 rd days compared with 1 st day.

- There was statistically significant increase in $\mathrm{P}-\mathrm{CMV}$ in 2 nd and $3 \mathrm{rd}$ days compared with 1 st day.

Table (3): Comparison of Oxygenation Index between the Studied Groups.

There was statistically significant decrease in late HFOV and P-CMV groups compared with Early HFOV group in the 1 st, 2 nd and 3 rd days.

Fig. (1) show that regarding Oxygenation index:

There was statistically significant decrease in late HFOV in 3 rd days compared with 1 st day.

There was statistically significant decrease in $\mathrm{P}-\mathrm{CMV}$ in 3 rd days compared with 1 st and $2^{\text {nd }}$ days.

Table (4): Show that regarding Univariate and Multivariate Analysis for the Parameters Affecting Early high frequency oscillatory ventilation:

Oxygenation index was significant as a predictor for early HFOV success.

Fig. (2): ROC curve for oxygenation index to prognosis cases early high frequency oscillatory ventilation.

Oxygenation index was significant with cut off value $>13$, sensitivity 73.33 , specificity 66.67 , PPV 68.7 and NPV 71.4. 
Table (1): Comparison of demographic data between the studied groups.

\begin{tabular}{|c|c|c|c|c|c|c|c|c|}
\hline & \multicolumn{4}{|c|}{ HFOV $(n=20)$} & & & \multirow{3}{*}{$\begin{array}{l}\text { Test } \\
\text { of sig. }\end{array}$} & \multirow{3}{*}{$p$} \\
\hline & \multicolumn{2}{|c|}{ Early $(n=15)$} & \multicolumn{2}{|c|}{ Late $(n=5)$} & \multicolumn{2}{|c|}{ P-CMV $(n=10)$} & & \\
\hline & No. & $\%$ & No. & $\%$ & No. & $\%$ & & \\
\hline \multicolumn{9}{|l|}{ Sex: } \\
\hline Male & 7 & 46.7 & 2 & 40.0 & 5 & 50.0 & $\chi^{2}=0.274$ & $\mathrm{MC}_{p}=1.000$ \\
\hline Female & 8 & 53.3 & 3 & 60.0 & 5 & 50.0 & & \\
\hline \multicolumn{9}{|l|}{ Age (month): } \\
\hline Min.-Max. & \multirow{2}{*}{\multicolumn{2}{|c|}{$\begin{array}{l}2.50-24.0 \\
8.83 \pm 5.81\end{array}$}} & \multicolumn{2}{|c|}{$2.50-40.0$} & \multicolumn{2}{|c|}{$2.0-108.0$} & & \\
\hline Mean \pm SD & & & \multirow{2}{*}{\multicolumn{2}{|c|}{$\begin{array}{l}15.10 \pm 15.06 \\
9.0\end{array}$}} & \multicolumn{2}{|c|}{$\begin{array}{l}21.90 \pm 32.64 \\
10.0\end{array}$} & $H=0.563$ & 0.755 \\
\hline Median & \multicolumn{2}{|l|}{8.0} & & & & & & \\
\hline \multicolumn{9}{|l|}{ Height $(\mathrm{cm})$ : } \\
\hline Min.-Max. & \multirow{2}{*}{\multicolumn{2}{|c|}{$\begin{array}{l}55.0-90.0 \\
65.87 \pm 9.83\end{array}$}} & \multirow{2}{*}{\multicolumn{2}{|c|}{$\begin{array}{l}55.0-95.0 \\
73.0 \pm 18.15\end{array}$}} & \multicolumn{2}{|c|}{$50.0-140.0$} & $F=1355$ & \\
\hline Mean \pm SD & & & & & 78.50 & 27.99 & $\mathrm{~F}=1.355$ & $0.2 / 5$ \\
\hline Median & \multicolumn{2}{|l|}{62.0} & \multicolumn{2}{|l|}{63.0} & \multicolumn{2}{|c|}{72.50} & & \\
\hline \multicolumn{9}{|l|}{ Weight $(\mathrm{Kg})$ : } \\
\hline Min.-Max. & \multicolumn{2}{|c|}{$3.50-15.0$} & \multicolumn{2}{|c|}{$5.0-15.0$} & \multicolumn{2}{|c|}{$3.0-25.0$} & & \\
\hline Mean \pm SD & \multicolumn{2}{|c|}{$7.03 \pm 3.43$} & \multicolumn{2}{|c|}{$8.80 \pm 4.44$} & \multicolumn{2}{|c|}{$10.25 \pm 6.45$} & $\mathrm{H}=1.998$ & 0.368 \\
\hline Median & \multicolumn{2}{|l|}{6.0} & \multicolumn{2}{|c|}{6.0} & \multicolumn{2}{|l|}{9.50} & & \\
\hline \multicolumn{9}{|c|}{$\begin{array}{l}\chi^{2}, \mathrm{p}: \chi^{2} \text { and } \mathrm{p} \text { values for Chi square test for } \mathrm{c} \\
\mathrm{MCp}: p \text {-value for Monte Carlo for Chi square } \\
\mathrm{H}, \mathrm{p}: \text { H and } p \text {-values for Kruskal Wallis test. } \\
\mathrm{F}, \mathrm{p}: \text { : F and } p \text {-values for ANOVA test. } \\
\mathrm{CMV}: \text { Conventional mechanical ventilation. } \\
\text { HFOV : High frequency oscillatory ventilation. } \\
\text { Data are represented as mean } \pm \text { SD. }\end{array}$} \\
\hline
\end{tabular}

Table (2): Comparison of Oxygen Saturation (\%) between the Studied Groups.

\begin{tabular}{|c|c|c|c|c|c|}
\hline $\mathrm{O}_{2}$ Sat & 1 st day & 2nd day & $3^{\text {rd day }}$ & $\mathrm{F}$ & $p$ \\
\hline \multicolumn{6}{|l|}{ HFOV early: } \\
\hline Min.-Max. & $70.0-73.0$ & $68.0-80.0$ & $67.0-87.0$ & & \\
\hline Mean \pm SD & $71.93 \pm 1.28$ & $74.20 \pm 4.71$ & $76.33 \pm 8.18$ & $4.983 *$ & $0.014^{*}$ \\
\hline Median & 72.0 & 75.0 & 80.0 & & \\
\hline Sig. bet. periods. & \multicolumn{5}{|c|}{$p_{3}=0.048^{*}, p_{4}=0.041 *, p_{5}=0.044 *$} \\
\hline \multicolumn{6}{|l|}{ HFOV late: } \\
\hline Min.- Max. & $55.0-70.0$ & $77.0-95.0$ & $83.0-95.0$ & & \\
\hline Mean \pm SD & $63.80 \pm 6.06$ & $86.80 \pm 7.63$ & $90.20 \pm 4.76$ & $43.240^{*}$ & $<0.001 *$ \\
\hline Median & 63.0 & 85.0 & 92.0 & & \\
\hline Sig. bet. periods. & \multicolumn{5}{|c|}{$p_{3}=0.002 *, p_{4}=0.002 *, p_{5}=0.226$} \\
\hline \multicolumn{6}{|l|}{$P-C M V:$} \\
\hline Min. - Max. & $50.0-70.0$ & $93.0-100.0$ & $93.0-100.0$ & \multirow{3}{*}{$282.148 *$} & \multirow{3}{*}{$<0.001 *$} \\
\hline Mean \pm SD & $63.90 \pm 6.77$ & $96.10 \pm 2.08$ & $96.30 \pm 2.0$ & & \\
\hline Median & 66.50 & 96.0 & 96.50 & & \\
\hline Sig. bet. periods. & \multicolumn{5}{|c|}{$p_{3}<0.001 *, p_{4}<0.001 *, p_{5}=0.619$} \\
\hline F2 & $11.309^{*}$ & 68.163 & 32.170 & & \\
\hline$p_{2}$ & $<0.001^{*}$ & $<0.001 *$ & $<0.001^{*}$ & & \\
\hline
\end{tabular}

$F 1, p_{1}: \mathrm{F}$ and $p$-values for ANOVA with repeated measures test for comparing between different periods. $F 2, p_{2}: \mathrm{F}$ and $p$-values for ANOVA test for comparing between the three groups.

$p_{3}: p$-value for 1 st day and 2 nd day.

$p_{4}: p$-value for 1 st day and 3 rd day.

$p_{* 5} \quad: p$-value for 2 nd day and 3 rd day. : Statistically significant at $p \leq 0.05$.

CMV : Conventional mechanical ventilation.

HFOV : High frequency oscillatory ventilation. 
Table (3): Comparison of oxygenation index between the studied groups.

\begin{tabular}{|c|c|c|c|c|c|}
\hline Oxygenation index & 1 st day & 2nd day & $3 \mathrm{rd} \mathrm{d}_{\mathrm{ay}}$ & $\mathrm{Fr}_{\chi}^{2}$ & $p_{1}$ \\
\hline \multicolumn{6}{|l|}{ HFOV early: } \\
\hline Min.- Max. & $13.0-17.0$ & $8.0-18.0$ & $5.0-20.0$ & \multirow{3}{*}{0.414} & \multirow{3}{*}{0.813} \\
\hline Mean \pm SD & $14.67 \pm 1.45$ & $13.07 \pm 3.84$ & $12.60 \pm 5.89$ & & \\
\hline Median & 14.0 & 12.0 & 10.0 & & \\
\hline \multicolumn{6}{|l|}{ HFOV late: } \\
\hline Min.- Max. & $11.0-14.0$ & $6.0-11.0$ & $5.0-9.0$ & \multirow{3}{*}{$9.579 *$} & \multirow{3}{*}{$0.008^{*}$} \\
\hline Mean $\pm \mathrm{SD}$ & $11.80 \pm 1.30$ & $8.60 \pm 1.82$ & $7.16 \pm 2.01$ & & \\
\hline Median & 11.0 & 9.0 & 8.0 & & \\
\hline Sig. bet. periods. & \multicolumn{3}{|c|}{$p_{3}=0.082, p_{4}=0.003 *, p_{5}=0.206$} & \multirow{5}{*}{$16.200^{*}$} & \multirow{5}{*}{$<0.001 *$} \\
\hline \multirow{4}{*}{$\begin{array}{l}P-C M V: \\
\quad \text { Min. - Max. } \\
\text { Mean } \pm \text { SD } \\
\text { Median }\end{array}$} & & & & & \\
\hline & $10.0-16.10$ & $8.0-15.60$ & $5.0-11.0$ & & \\
\hline & $12.75 \pm 1.94$ & $11.52 \pm 2.37$ & $6.90 \pm 1.97$ & & \\
\hline & 12.30 & 11.50 & 7.0 & & \\
\hline Sig. bet. periods. & \multicolumn{3}{|c|}{$p_{3}=0.044^{*}, p_{4}<0.001 *, p_{5}=0.044^{*}$} & & \\
\hline $\mathrm{H}$ & $10.095^{*}$ & 6.256 & 7.257 & & \\
\hline $\mathrm{p}_{2}$ & $0.006^{*}$ & $0.044 *$ & $0.027 *$ & & \\
\hline $\begin{array}{ll}\mathrm{Fr}_{\chi}{ }^{2}, p 1: \text { Chi square an } \\
\mathrm{H}, p^{2} & : \mathrm{H} \text { and } p \text {-valu } \\
p 3 & : p \text {-value for } 1 \\
p 4 & : p \text {-value for } 1 \\
p_{*} 5 & : p \text {-value for } \\
& : \text { Statistically s }\end{array}$ & $\begin{array}{l}p \text {-value for Fri } \\
\mathrm{s} \text { for Kruskal W } \\
\text { day and }{ }_{2} \mathrm{rd} \text { da } \\
{ }_{d} \text { day and }{ }^{2} \text { day } \\
\text { day and } 33^{\text {rd da }} \\
\text { gnificant at } p \leq 0\end{array}$ & $\begin{array}{l}\text { man test for co } \\
\text { is test }\end{array}$ & ring between $\mathrm{d}$ & rent periods & each group \\
\hline \multicolumn{6}{|c|}{$\begin{array}{l}\text { P-CMV : Conventional mechanical ventilation } \\
\text { HFOV : High frequency oscillatory ventilation }\end{array}$} \\
\hline
\end{tabular}

Table (4): Univariate and multivariate analysis for the parameters affecting early high frequency oscillatory ventilation.

\begin{tabular}{lcccc}
\hline & \multicolumn{3}{c}{ Univariate } & \#Multivariate \\
\cline { 2 - 5 } & $p$ & OR (95\%C. I) & $p$ & OR (95\%C. I) \\
\hline Sex (Female) & 1.000 & $1.000(0.238-4.198)$ & & \\
Age (month) & 0.214 & $0.951(0.877-1.030)$ & & \\
Height & 0.148 & $0.964(0.916-1.013)$ & & \\
Weight & 0.140 & $0.868(0.719-1.047)$ & & \\
Hb & 0.396 & $0.835(0.550-1.266)$ & & \\
WBCs (x10 $\left.{ }^{3}\right)$ & 0.293 & $0.923(0.795-1.072)$ & & \\
PLTs (x10 $\left.{ }^{3}\right)$ & 0.871 & $1.001(0.992-1.010)$ & & \\
CRP & 0.681 & $0.991(0.948-1.035)$ & & \\
MABP (mmHg) & 0.833 & $1.006(0.952-1.063)$ & & \\
Oxygenation index & $0.007 *$ & $2.306(1.527-4.229)$ & $0.010^{*}$ & 2.300 (1.216-4.349) @ \\
O ${ }_{2}$ Sat & 0.993 & - & & \\
CO & 0.122 & $0.186(0.022-1.567)$ & & \\
CI & 0.826 & $0.902(0.359-2.265)$ & & \\
SV & 0.124 & $0.183(0.021-1.590)$ & & \\
SVI & 0.162 & $0.861(0.699-1.062)$ & \\
SVR & 0.268 & $1.000(1.0-1.0)$ & \\
SVRI & 0.512 & $1.000(1.0-1.0)$ & \\
TI & 0.999 & - & & \\
\hline
\end{tabular}

OR: Odd`s ratio. C.I: Confidence interval. \# : All variables with $p<0.05$ was included in the multivariate. @ : Adjust Odd`s ratio by age and sex. $\quad *$ : Statistically significant at $p \leq 0.05$. 


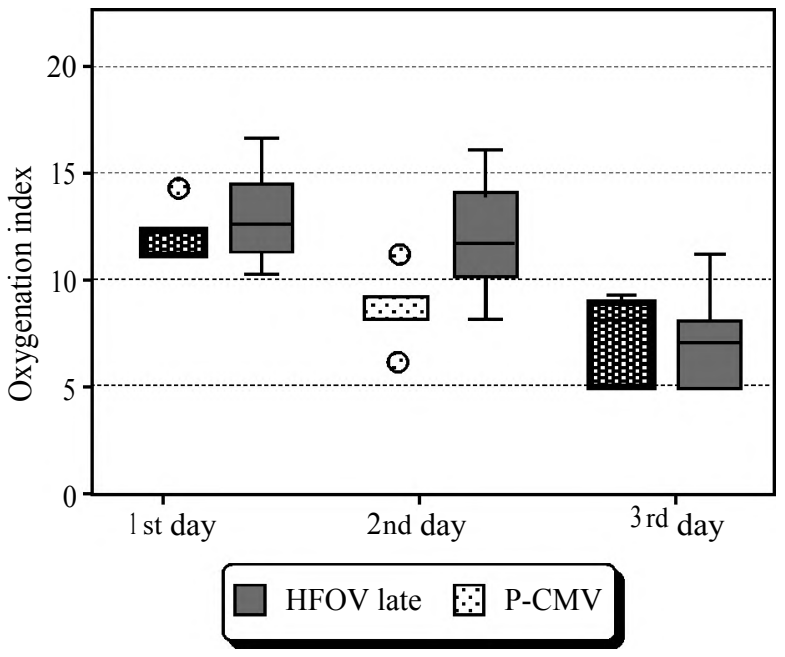

Fig. (1): Comparison of oxygenation index between studied groups.

\section{Discussion}

For over 20 years, high frequency oscillatory ventilation has been a staple in the management of children with acute respiratory failure. HFOV is a mode of mechanical ventilation that recruits diseased lung and improves oxygenation through the use of high mean airway pressures with tidal volumes less than anatomic dead space. Although HFOV is commonly used in children, efficacy data are limited and predate the era of low tidal volume conventional mechanical ventilation [8] .

A commonly accepted strategy for initiation of HFOV is to maximize airway recruitment by placing a patient on an oscillatory ventilator at a MAP higher than P-CMV. In this "high-volume" strategy, the patient is ventilated at a higher MAP, but with less PIP and less VT variation [9].

The negative impact on $\mathrm{CO}$ made by $\mathrm{P}-\mathrm{CMV}$ is secondary to decreased venous return, compression of the pulmonary vascular bed, and a shift of the interventricular septum. This negative impact could be worsened by HFOV because higher MAP is used. Because patients who are candidates for HFOV often have hemodynamic compromise, they may not tolerate a significant alteration in their CO [10].

The objective of this study was to compare the effects of early HFOV versus late HFOV and PCMV on some HD parameters in critically ill children admitted to Tanta PICU. It was carried out on 30 children, 15 males, 15 females, from 2 to 108 months. Patients were divided into three groups: Group I (Early HFOV), Group II Late) HFOV) and Group III (P-CMV): Each group was hemodynamically monitored for three consecutive

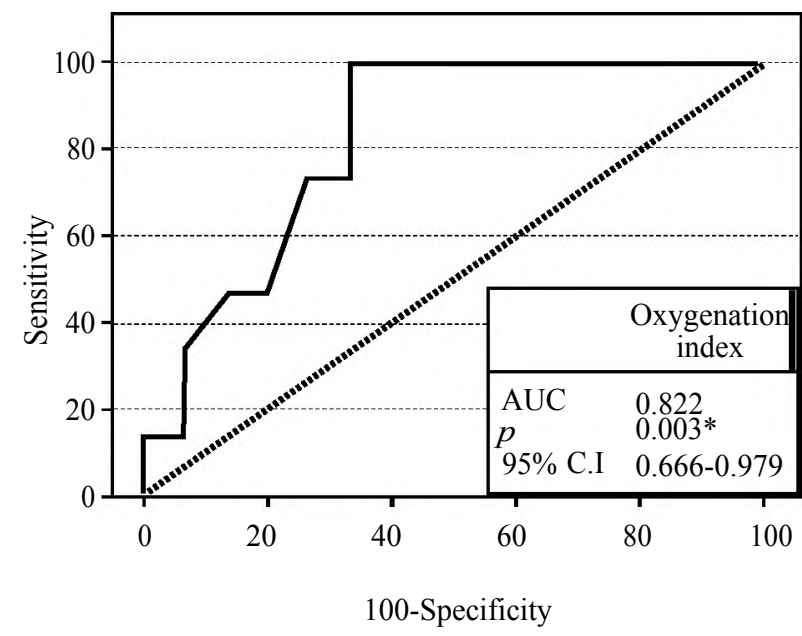

Fig. (2): ROC curve for oxygenation index to prognosis cases early high frequency oscillatory ventilation

days. This study was conducted between December 2016 to December 2017.

The present study showed that regarding age, weight and sex there was no significant difference in age and sex in early HFOV compared with late HFOV/P-CMV. The present study showed that regarding PRISM there was no significant difference between studied groups during study period. The non-significant difference found in age, weight, sex and PRISM III score demonstrates the nonbias choice of the study cases.

The present study showed that regarding HR there was no significant difference between studied groups during study period. This was in accordance with Mehta S et al., [11] who found no significant differences in HR in HFOV (early and late) and CVM groups over the initial 72 hours of treatment. Similarly, Guttormsen et al., [12] who found no changes in HR noted during transition from CMV to HFOV.

The present study showed that regarding MABP there was no significant difference between studied groups during study period. This was in accordance with Levin D L et al., [13] . who found that there was no significant difference between patients undergoing early and late HFOV versus those submitted to CMV within the first 72 hours of treatment regarding MABP.

The present study showed that Hb, WBCs, PLTs and CRP there was no significant difference between studied groups during study period. The non-significant difference proved in $\mathrm{Hb}$, WBCs, PLTs and CRP demonstrates the non-bias choice of the cases. 
The present study showed that regarding $\mathrm{O}_{2} \mathrm{Sat}$ There was significant decrease of $\mathrm{O}_{2}$ Sat of Early HFOV compared with P-CMV and Late HFOV in 1 st, 2 nd and 3 rd days. Also, there was significant increase in Early HFOV in 2 nd and 3 rd days compared with ${ }^{1 \text { st }}$ day. Likewise, there was significant increase in Late HFOV in 2 nd and 3 rd days compared with ${ }^{1 \text { st }}$ day. Similarly, there was significant increase in P-CMV in 2 nd and 3 rd days compared with ${ }^{1 \text { st }}$ day.

This was in accordance with, Pinzon et al., [14] who conducted a study to show the effects of Late HFOV in children with ARDS after failure of CMV. They found that after 48 hours of HFOV, a significant increase in $\mathrm{O}_{2}$ Sat was achieved. Equally, Moniza et al., [15] found that with Late HFOV, immediate and significant increase was achieved in the $\mathrm{O}_{2} \mathrm{Sat} / \mathrm{F}_{\mathrm{i}} \mathrm{O}_{2}$ ratio that was sustained until 24 hours of HFOV after transition from CMV.

The present study showed that regarding $\mathrm{F}_{\mathrm{i}} \mathrm{O}_{2}$ There was significant decrease in Early HFOV in 3 rd day compared with ${ }^{1 \text { st }}$ day. This was in accordance with Mohamed et al., [16] who found that after 3 hrs. From starting HFOV, patients showed a significant decrease of $\mathrm{F}_{\mathrm{i}} \mathrm{O}_{2}$. Too, the HIFO trial [17] found that in the first 24 hours after randomization, infants on HFOV required lower $\mathrm{F}_{\mathrm{i}} \mathrm{O}_{2}$ when compared with infants on CMV. Likewise, Pinzon et al., [14] found that After 48 hours of HFOV, $\mathrm{F}_{\mathrm{i}} \mathrm{O}_{2}$ decrease. Moreover, Andersen et al., [12] found that within $4 \mathrm{~h}$ after transition from CMV to late $\mathrm{HFOV}$, there was a significant reduction in $\mathrm{F}_{\mathrm{i}} \mathrm{O}_{2}$.

The present study showed that regarding SV There was significant increase in P-CMV in 2 nd day compared with ${ }^{1 \text { st }}$ day.

The present study showed that regarding SVI There was significant increase in P-CMV in 2 nd and 3 rd days compared with ${ }^{1 \text { st }}$ day. This was in contrast With David et al., [18] . who conducted a study to show cardiovascular changes in patients with acute ARDS during transition from P-CMV to late HFOV, using transesophageal echocardiography and invasive hemodynamic monitoring. They reported that during HFOV there were decreased SVI.

The present study showed that regarding $\mathrm{CO}$ there was no significant difference between studied groups. However, there was significant increase in cardiac output in the 2 nd, 3 rd days compared with ${ }^{1 \text { st }}$ day in late HFOV group. This was in accordance with Gutierrez et al., [13] who found that there was no evidence of decrease $\mathrm{CO}$ after transition from CMV to late HFOV. They explained that by that they used enough pressure to obtain adequate oxygenation but reduced pressures when lung compliance and oxygenation were improved. Additionally, Kinsella et al., [19] showed that there were no deleterious cardiovascular effects were observed with Late HFOV or IMV. In addition, Vincent et al., [20] observed that there were no hemodynamic effects on cardiac post-operative patients ventilated with low MAP Late HFOV compared with CMV. Likewise, Derdak et al., [11] found no significant differences in $\mathrm{CO}$ in late HFOV and CVM groups over the initial 72 hours of treatment. Moreover, Pinzon et al., [14] who found that although $\mathrm{CO}$ was not measured in their study, the observed hemodynamic performance suggests that there was no additional blood flow impairment in their patients, as MABP remained stable and HR decreased. However, this was in contrast also with Mehta et al., [21] who showed that Late HFOV can lead to increased filling pressures and significant decrease in $\mathrm{CO}$.

The present study showed that regarding CI there was no significant difference between studied groups. Which may be explained by the small number of the studied cases (Pilot study). This was in accordance with Gutierrez et al., [13] who found that CI did not change significantly in the group as a whole after transition from CMV to late HFOV.

The present study showed that regarding SVR There was no significant difference between the studied groups. This was in contrast with Goodman et al., [22] who found that SVR and MABP were reduced immediately after late HFOV was initiated after failure of CMV.

The present study showed that regarding SVRI there was there was no significant difference between the studied groups. This was in accordance with Gutierrez et al., [13] who found no significant changes in SVRI after transition from CMV to late HFOV. This may be explained by that SVRI decreased as a compensation of increase of $\mathrm{CO}$ in HFOV in the 3 rd day compared with ${ }^{1 \text { st }}$ day. There was non-significant decrease in MAP and AP as time pass. However, the non-significant decrease may be explained by the small number of the studied cases. (Pilot study).

The present study showed that There was significant decrease in PIP in the 2 nd and 3 rd days compared with ${ }^{1 \text { st }}$ day. There was significant decrease in RR in the 2 nd day compared with ${ }^{1 \text { st }}$ day.

The present study showed that regarding Oxygenation Index There was significant decrease in late HFOV and P-CMV groups compared with 
Early HFOV group in the 1 st, 2 nd and 3 rd days. There was significant decrease in late HFOV in 3 rd days compared with 1 st and 2 nd days. It is one of most important prognostic factors for detection timing of HFOV according to ROC curve for oxygenation index to prognosis cases early HFOV.

The present study showed that regarding regression analysis Oxygenation index was significant as a predictor for early HFOV success.

The present study showed that regarding ROC curve; oxygenation index was significant as a prognostic test with early HFOV with cut off value $>13$, sensitivity 73.33 , specificity 66.67 , PPV 68.7 and NPV 71.4.

This was in accordance with Ritacca FV, [23] who found OI was associated with mortality independently of other disease markers and could be important for selecting ARDS patients that could benefit from HFOV.

\section{Conclusion:}

As hypoxia worsened, patient percentage with Early HFOV increased. Oxygenation index was significant as a predictor and prognostic factor for early HFOV success.

\section{Acknowledgments:}

This research was carried out without funding.

\section{Conflicts of interest:}

No conflicts of interest declared.

\section{Authors' Contributions:}

All authors had equal role in design, work, statistical analysis and manuscript writing. All authors have approved the final article work.

\section{References}

1- SANTSCHI M. and RANDOLPH A.G.: Pediatric Acute Lung Injury Mechanical Ventilation Investigators. Pediatr. Crit. Care. Med., 14 (7): e-332-7, 2013.

2- AUGUSTUS L. and CRITCHLEY H.: Minimally Invasive Cardiac Output Monitoring, In: Wilbert S. Aronow (Ed.), Artery Bypass, In. Tech., Croatia, p. 45, 2012.

3- TIBBY S.M. and MURDOCH I.A.: Monitoring cardiac function in intensive care. Arch. Dis. Child., 88: 46-52, 2003.

4- HEUER J.F., SAUTER P., BARWING J., HERRMANN P., CROZIE T.A., BLECKMANN A., et al.: Effects of high-frequency oscillatory ventilation on systemic and cerebral hemodynamics and tissue oxygenation: An experimental study in pigs. Neurocrit. Care., 17: 281-92, 2012.
5- IP T. and MEHTA S.: The role of high-frequency oscillatory ventilation in the treatment of acute respiratory failure in adults. Curr. Opin. Crit. Care., 18: 70-9, 2012.

6- FORT P., FARMER C., WESTERMAN J., JOHANNIGMAN J., BENINATI W., DOLAN S., et al.: High-frequency oscillatory ventilation for adult respiratory distress syndrome-a pilot study. Crit. Care. Med., 25: 937-47, 1997.

7- MEHTA S., LAPINSKY S.E., HALLETT D., et al. Prospective trial of high-frequency oscillation in adults with acute respiratory distress syndrome. Crit. Care. Med., 29: 1360-9, 2001

8- SANTSCHI M. and RANDOLPH A.G.: Pediatric Acute Lung Injury Mechanical Ventilation Investigators. Pediatr. Crit. Care. Med. 14 (7): e-332-7, 2013.

9- ARNOLD J.H., TRUOG R.D., THOMPSON J.E. and FACKLER J.C.: High-frequencyOscillatory ventilation in pediatric respiratory failure. Crit. Care. Med., 21: 2728, 1993.

10- RANKIN J.S., OLSEN C.O., ARENTZEN C.E., TYSON G.S., MAIER G., SMITH P.K., et al.: The effects of airway pressure on cardiac function in intact dogs and man. Circulation. 66: 108-20, 1982.

11- DERDAK S., MEHTA S., STEWART T.E., SMITH T., ROGERS M., BUCHMAN T.G., et al.: High-frequency oscillatory ventilation for acute respiratory distress syndrome in adults: A randomized, controlled trial. Am. J. Respir. Crit. Care. Med., 166: 801-8, 2002.

12-ANDERSEN F.A., GUTTORMSEN A.B. and FLAATTEN H.K.: High-frequency oscillatory ventilation in adult patients with acute respiratory distress syndrome - a retrospective study. Acta. Anaesthesiol. Scand, 46: 10828, 2002.

13- GUTIERREZ J.A., LEVIN D.L. and TORO-FIGUEROA L.O.: Hemodynamic effects of high frequency oscillatory ventilation in severe pediatric respiratory failure. Intensive Care. Med., 21: 505- 10, 1995.

14- PINZONA D.A., ROCHA T.S., RICACHINEVSKYA C., PIVA J.P. and FRIEDMANB G.: High-frequency oscillatory ventilation in children with acute respiratory distress syndrome: experience of a pediatric intensive care unit. REV ASSOC MED BRAS., 59 (4): 368-74, 2013.

15- MONIZA M., SILVESTREB C., NUNESB P., ABADESSOB C., MATIASB E., LOUREIROB H., et al.: High-frequency oscillatory ventilation in children: A 10-year experience. J. Pediatr. (Rio. J.), 89 (1): 48-55, 2013.

16- MOHAMED S-A.R. and MOHAMED N.N.: Efficacy and adverse events of early high-frequency oscillatory ventilation in adult burn patients with acute respiratory distress syndrome, Egypt J. Anaesth., 1-9, 2016.

17- HIFO Study Group. Randomized study of high-frequency oscillatory ventilation in infants with severe respiratory distress syndrome. J. Pediatr., 122: 609-19, 1993.

18- DAVID M., VON BARDELEBEN R.S., WEILER N., MARKSTALLER K., SCHOLZ A.J., et al.: Cardiac function and haemodynamics during transition to highfrequency oscillatory ventilation. Euro. J. Anaesthesiol., 21 (12): 944-52, 2004 
19- KINSELLA J.P., GERSTMANN D.R., CLARK R.H., NULL D.M. Jr, MORROW W.R., TAYLOR A.F., et al.: High-frequency oscillatory ventilation versus intermittent mandatory ventilation: Early hemodynamic effects in the premature baboon with hyaline membrane disease. Pediatr. Res., 29: t60-6, 1991.

20- VINCENT R.N., STARK A.R., LANG P., CLOSE R.H., NORWOOD W.I., CASTANEDA A.R., et al.: Hemodynamic response to high-frequency ventilation in infants following cardiac surgery. Pediatrics, 73: 426-30, 1985.
21- MEHTA S., GRANTON J., MACDONALD R.J., BOWMAN D., MATTE-MARTYNA, BACHMAN T., et al.: High-frequency oscillatory ventilation in adults: The Toronto experience. Chest., 126: 518-27, 2004.

22- GOODMAN M.A. and POLLACK M.: Hemodynamic effects of High-Frequency Oscillatory Ventilation in Children. Pediatric Pulmonology, 25: 371-4, 1998.

23- RITACCA F.V. and STEWART T.E.: Clinical review: high-frequency oscillatory ventilation in adults - a review of the literature and practical applications. Crit. Care. , 7: 385-390. 10.1186/cc2182, 2003

\section{التهوية التذبذبية عالية التردد المبكرة فى حالات الفشل التنفسى الحاد فى الأطفال}

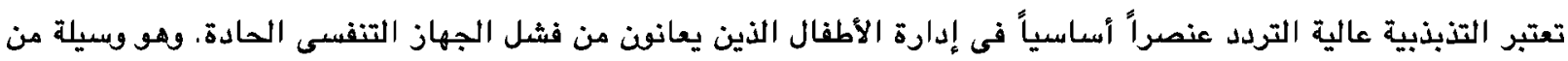

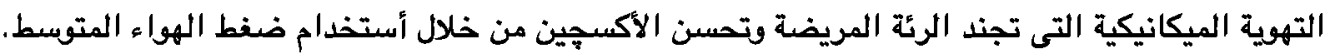

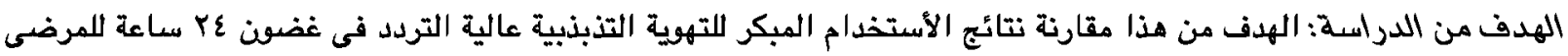

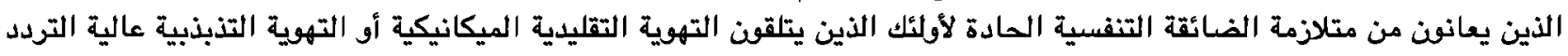

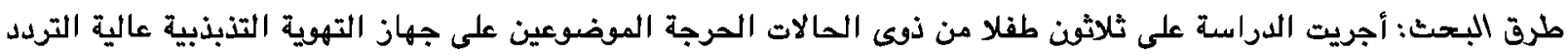

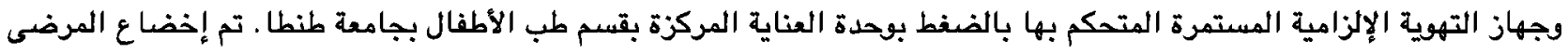

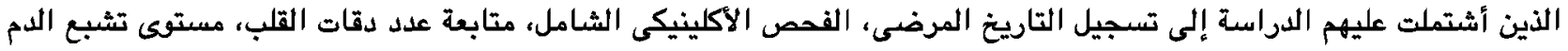

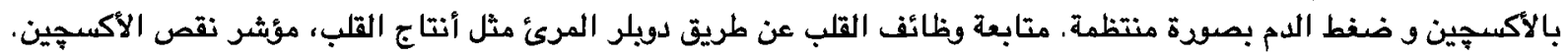

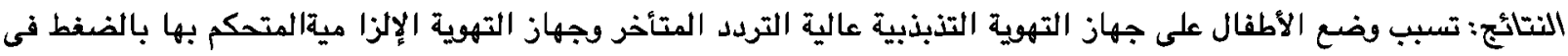
تقليل مؤشر نقص التنفس على الأطفال الذين تم وضعهم على جهاز التهوية التذبذبية عالية التردد المبكر.

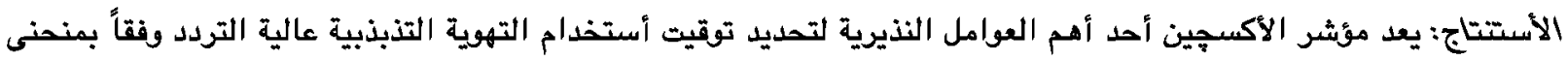
ROC يعتبر مؤشر نقص الاكسبين كمتنبئ لأستخدام جهاز التهوية التذبذبية التهبية عالية التردد المبكر.

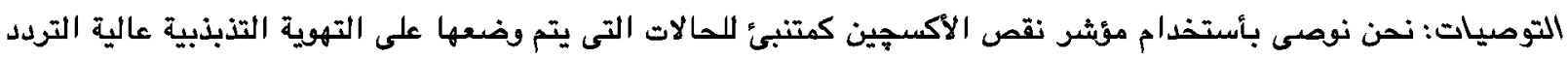

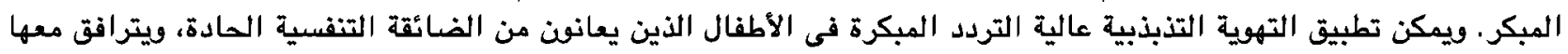

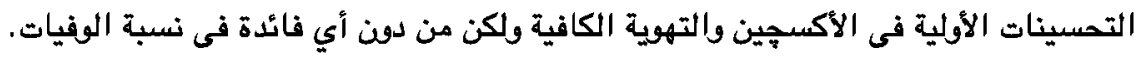

